Original Article

\title{
Influence of the length of hospitalisation in post-discharge outcomes in patients with acute heart failure: Results of the LOHRCA study
}

Òscar Miróa $^{\mathrm{a}, \mathrm{b}, *, 1}$, Joan Padrosa ${ }^{\mathrm{a}, 1}$, Koji Takagi ${ }^{\mathrm{c}}$, Étienne Gayat ${ }^{\mathrm{c}}$, Víctor Gil ${ }^{\mathrm{a}}$, Pere Llorens ${ }^{\mathrm{d}}$, Francisco Javier Martín-Sánchez ${ }^{\mathrm{e}}$, , Pablo Herrero-Puente ${ }^{\mathrm{g}}$, Javier Jacob ${ }^{\mathrm{h}}$, María Mir Montero ${ }^{\mathrm{i}}$, Josep Tost ${ }^{j}$, María Pilar López Díez ${ }^{\mathrm{k}}$, Lissete Traveria ${ }^{1}$, Raquel Torres-Gárate ${ }^{\mathrm{m}}$, María Isabel Alonso ${ }^{\mathrm{n}}$, Carmen Agüera ${ }^{\circ}$, Amparo Valero ${ }^{\mathrm{p}}$, Patricia Javaloyes ${ }^{\mathrm{d}}$, W. Frank Peacock ${ }^{\mathrm{b}, \mathrm{q}}$, Héctor Bueno ${ }^{\mathrm{f}, \mathrm{r}}$, Alexandre Mebazaa ${ }^{\mathrm{b}, \mathrm{c}}$, on behalf of the ICA-SEMES Research Group, Marta Fuentes ${ }^{\mathrm{s}}$, Cristina Gil ${ }^{\mathrm{s}}$, Héctor Alonso ${ }^{\mathrm{t}}$, Pablo Garmilat, Guillermo Llopis García ${ }^{u}$, María Cecilia Yáñez-Palma ${ }^{u}$, Sergio Iglesias López ${ }^{u}$, Rosa Escodav, Carolina Xipell ${ }^{v}$, Carolina Sánchez ${ }^{v}$, Josep María Gaytan`, María José Pérez-Duráw ${ }^{w}$ Eva Salvo ${ }^{\mathrm{w}}$, José Pavón $^{\mathrm{x}}$, Antonio Noval ${ }^{\mathrm{y}}$, José Manuel Torres ${ }^{\mathrm{z}}$, María Luisa López-Grima ${ }^{\mathrm{aa}}$, Amparo Valero ${ }^{\text {aa }}$, Marian Ángeles Juan $^{\mathrm{aa}}$, Alfons Aguirre ${ }^{\mathrm{ab}}$, Julián Errasti Morales ${ }^{\mathrm{ab}}$, Silvia Mínguez Masóa ${ }^{\mathrm{ab}}$, María Isabel Alonso $^{\mathrm{ac}}$, Francisco Ruiz ${ }^{\mathrm{ac}}$, José Miguel Franco ${ }^{\mathrm{ad}}$, Ana Belén Mecina ${ }^{\mathrm{ae}}$, Josep Tost ${ }^{\mathrm{af}}$, Susana Sánchez ${ }^{\mathrm{ag}}$, Virginia Carbajosa ${ }^{\mathrm{ag}}$, Pascual Piñera ${ }^{\mathrm{ah}}$, José Andrés Sánchez Nicolás ${ }^{\mathrm{ah}}$, Raquel Torres Garate ${ }^{\mathrm{ai}}$, Aitor Alquezar ${ }^{\mathrm{aj}}$, Miguel Alberto Rizzi ${ }^{\text {aj }}$, Sergio Herrera ${ }^{\mathrm{aj}}$, Alex Roset ${ }^{\mathrm{ak}}$, Irene Cabello $^{\text {ak }}$, Fernando Richard ${ }^{\text {al }}$, José María Álvarez Pérez ${ }^{\text {al }}$, María Pilar López Diez ${ }^{\text {al }}$, Joaquín Vázquez Álvarez ${ }^{\mathrm{am}}$, Belén Prieto García ${ }^{\mathrm{am}}$,

María García García yMarta Sánchez González ${ }^{\text {am }}$, Patricia Javaloyes ${ }^{\text {an }}$, Víctor Marquina ${ }^{\text {an }}$, Inmaculada Jiménez ${ }^{\text {an }}$, Néstor Hernández ${ }^{\text {an }}$, Benjamín Brouzet ${ }^{\text {an }}$, Sergio Ramos $^{\text {an }}$, Ana López ${ }^{\text {an }}$, Juan Antonio Andueza ${ }^{\mathrm{ao}}$, Rodolfo Romero ${ }^{\mathrm{ap}}$, Martín Ruíz ${ }^{\mathrm{aq}}$, Roberto Calvache ${ }^{\mathrm{aq}}$, María Teresa Lorca $^{\text {ar }}$, Luis Calderón ${ }^{\text {ar }}$, Beatriz Amores Arriaga ${ }^{\text {as }}$, Beatriz Sierra ${ }^{\text {as }}$, Enrique Martín Mojarro ${ }^{\text {at }}$, Lisette Travería Bécquer ${ }^{\mathrm{au}}$, Guillermo Burillo ${ }^{\mathrm{au}}$, Lluís Llauger García ${ }^{\mathrm{av}}$, Gerard Corominas LaSalle $^{\text {av }}$, Carmen Agüera Urbano ${ }^{\text {aw }}$, Ana Belén García Soto ${ }^{\text {aw }}$, Elisa Delgado Padial ${ }^{\text {aw }}$, Ester Soy Ferrer ${ }^{\text {ax }}$, Manuel Garrido ${ }^{\text {ay }}$, Francisco Javier Lucas ${ }^{\mathrm{az}}$, Rut Gaya $^{\mathrm{ba}}$, Carlos Bibiano ${ }^{\mathrm{bb}}$, María Mir ${ }^{\mathrm{bb}}$, Beatriz Rodríguez ${ }^{\mathrm{bb}}$, Natalia Sánchez ${ }^{\mathrm{bb}}$, José Luis Carballo $^{\mathrm{bc}}$, Esther Rodríguez-Adrada ${ }^{\mathrm{bd}}$, Belén Rodríguez ${ }^{\text {bd }}$

a Emergency Department, Hospital Clínic, Barcelona; "Emergencies: processes and pathologies” Research Group, IDIBAPS, University of Barcelona, Barcelona, Catalonia, Spain

${ }^{\mathrm{b}}$ The GREAT (Global REsearch in Acute Cardiovascular Conditions Team) Network, Rome, Italy

${ }^{\mathrm{c}}$ Department of Anesthesiology and Critical Care Medicine, Saint Louis Lariboisière University Hospital, Université Paris Diderot, Paris, France

${ }^{\mathrm{d}}$ Emergency Department, Home Hospitalization and Short Stay Unit, Hospital General de Alicante, Alicante, Spain

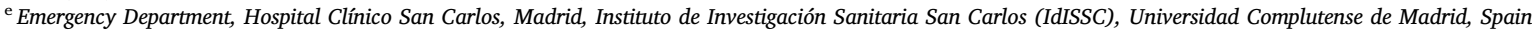

${ }^{\mathrm{f}}$ Centro Nacional de Investigaciones Cardiovasculares (CNIC), Madrid, Spain

${ }^{g}$ Emergency Department, Hospital Universitario Central de Asturias, Oviedo, Spain

${ }^{\mathrm{h}}$ Emergency Department, Hospital Universitari de Bellvitge, L'Hospitalet de Llobregat, Barcelona, Catalonia, Spain

${ }^{\mathrm{i}}$ Emergency Department, Hospital Universitario Infanta Leonor, Madrid, Spain

${ }^{\mathrm{j}}$ Emergency Department, Hospital de Terrassa, Barcelona, Catalonia, Spain

${ }^{\mathrm{k}}$ Emergency Department, Hospital Universitario de Burgos, Burgos, Spain

${ }^{1}$ Emergency Department, Hospital Universitario de Canarias, Tenerife, Spain

${ }^{\mathrm{m}}$ Emergency Department, Hospital Universitario Severo Ochoa, Leganés, Madrid, Spain

${ }^{\mathrm{n}}$ Emergency Department, Hospital Valme, Sevilla, Spain

${ }^{\circ}$ Emergency Department, Hospital Costa del Sol, Marbella, Málaga, Spain

\footnotetext{
* Corresponding author at: Emergency Department, Hospital Clínic, Villarroel 170, Barcelona, Catalonia 08036, Spain.

E-mail address: omiro@clinic.cat (Ò. Miró).
} 
${ }^{\mathrm{P}}$ Emergency Department, Hospital Doctor Peset, València, Spain

${ }^{\mathrm{q}}$ Emergency Department, Baylor College of Medicine, Ben Taub General Hospital, Houston, USA

${ }^{\mathrm{r}}$ Cardiology Department, Universidad Complutense, Hospital 12 de Octubre, Madrid, Spain

${ }^{\mathrm{s}}$ Hospital Universitario de Salamanca, Spain

${ }^{\mathrm{t}}$ Hospital Marqués de Valdecilla de Santander, Spain

${ }^{\mathrm{u}}$ Hospital Clínico San Carlos de Madrid,Spain

${ }^{\vee}$ Hospital Clínic de Barcelona, Spain

${ }^{\mathrm{w}}$ Hospital Politénic La Fe de Valencia, Spain

${ }^{\mathrm{x}}$ Hospital Dr. Negrín de Las Palmas de Gran Canaria, Spain

${ }^{y}$ Hospital Insular de Las Palmas de Gran Canaria, Spain

${ }^{\mathrm{z}}$ Hospital Reina Sofía de Córdoba, Spain

${ }^{\text {aa }}$ Hospital Dr. Peset de Valencia, Spain

${ }^{\text {ab }}$ Hospital del Mar de Barcelona, Spain

${ }^{\text {ac }}$ Hospital de Valme de Sevilla, Spain

${ }^{\text {ad }}$ Hospital Miguel Servet de Zaragoza, Spain

ae Hospital de Alcorcón de Madrid, Spain

${ }^{\text {af }}$ Consorci Sanitari de Terrassa, Spain

${ }^{\mathrm{ag}}$ Hospital Rio Ortega de Valladolid, Spain

${ }^{\text {ah }}$ Hospital Reina Sofía de Murcia, Spain

ai Hospital Severo Ochoa de Madrid, Spain

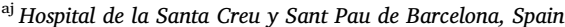

${ }^{\mathrm{ak}}$ Hospital Universitari de Bellvitge de Barcelona, Spain

${ }^{\text {al }}$ Hospital Universitario de Burgos, Spain

${ }^{a m}$ Hospital Universitario Central de Asturias de Oviedo, Spain

${ }^{\text {an }}$ Hospital General de Alicante, Spain

${ }^{\text {ao }}$ Hospital General Universitario Gregorio Marañón de Madrid, Spain

${ }^{\text {ap }}$ Hospital Getafe de Madrid, Spain

${ }^{\mathrm{aq}}$ Hospital de Henares de Madrid, Spain

${ }^{a r}$ Hospital del Tajo de Madrid, Spain

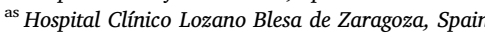

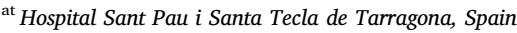

${ }^{\text {au }}$ Hospital Universitario de Canarias de Tenerife, Spain

${ }^{\mathrm{av}}$ Hospital Universitari de Vic de Barcelona, Spain

${ }^{\mathrm{aw}}$ Hospital Costa del Sol de Marbella de Málaga, Spain

${ }^{\text {ax }}$ Hospital Josep Trueta de Girona, Spain

${ }^{a y}$ Hospital Virgen Macarena de Sevilla, Spain

${ }^{a z}$ Hospital General de Albacete, Spain

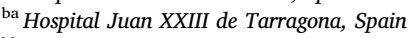

${ }^{\mathrm{bb}}$ Hospital Infanta Leonor de Madrid, Spain

bc Complejo Hospitalario Universitario de Ourense, Spain

${ }^{\text {bd } H o s p i t a l ~ R e y ~ J u a n ~ C a r l o s ~ d e ~ M o s t o l e s ~ d e ~ M a d r i d, ~ S p a i n ~}$

\section{A R T I C L E I N F O}

\section{Keywords:}

Acute heart failure

Length of hospitalisation

Post-discharge outcomes

Vulnerability phase

Mortality

Readmission

\section{A B S T R A C T}

Objective: To investigate the relationship between length of hospitalisation (LOH) and post-discharge outcomes in acute heart failure (AHF) patients and to ascertain whether there are different patterns according to department of initial hospitalisation.

Methods: Consecutive AHF patients hospitalised in 41 Spanish centres were grouped based on the LOH $(<6 / 6$ 10/11-15/> 15 days). Outcomes were defined as 90-day post-discharge all-cause mortality, AHF readmissions, and the combination of both. Hazard ratios (HRs), adjusted by chronic conditions and severity of decompensation, were calculated for groups with $\mathrm{LOH}>6$ days vs. $\mathrm{LOH}<6$ days (reference), and stratified by hospitalisation in cardiology, internal medicine, geriatrics, or short-stay units.

Results: We included 8563 patients (mean age: $80(\mathrm{SD}=10$ ) years, 55.5\% women), with a median LOH of 7 days (IQR 4-11): 2934 (34.3\%) had a LOH < 6 days, 3184 (37.2\%) 6-10 days, 1287 (15.0\%) 11-15 days, and 1158 $(13.5 \%)>15$ days. The 90 -day post-discharge mortality was $11.4 \%$, readmission $32.2 \%$, and combined endpoint $37.4 \%$. Mortality was increased by $36.5 \%(95 \% \mathrm{CI}=13.0-64.9)$ when $\mathrm{LOH}$ was $11-15$ days, and by $72.0 \%$ (95\%CI $=42.6-107.5)$ when $>15$ days. Conversely, no differences were found in readmission risk, and the combined endpoint only increased $21.6 \%(95 \% \mathrm{CI}=8.4-36.4)$ for $\mathrm{LOH}>15$ days. Stratified analysis by hospitalisation departments rendered similar post-discharge outcomes, with all exhibiting increased mortality for $\mathrm{LOH}>15$ days and no significant increments in readmission risk.

Conclusions: Short hospitalisations are not associated with worse outcomes. While post-discharge readmissions are not affected by $\mathrm{LOH}$, mortality risk increases as the $\mathrm{LOH}$ lengthens. These findings were similar across hospitalisation departments.

\section{Introduction}

Heart failure (HF) is a world-wide pandemic associated with significant morbidity, mortality, and cost burden [1,2]. For every health

\footnotetext{
${ }^{1}$ Òscar Miró and Joan Padrosa have equally contributed to this study and should both be considered as first author.
}

care system, the majority of HF costs are related to hospitalisations during acute decompensations and are proportional to the length of hospitalisation (LOH) required [3]. Therefore, many efforts have been directed at shortening the $\mathrm{LOH}$ of patients with acute HF (AHF). Moreover, this strategy is potentially beneficial due to a reduction of the hazards associated with hospitalisation itself, which include exposure to nosocomial infection and complications, iatrogenic harm, or 
the development of delirium in the elderly. Shortening hospitalisation could also impact the rates of post-hospital syndrome, which occurs in recently hospitalised patients who are not only recovering from their acute illness, but also experience a transient period of generalised risk for a wide range of adverse health events [4]. In this sense, data on patients with AHF from the VERITAS trials demonstrated that longer LOH was associated with a higher rate of post-discharge mortality [5]. To meet the objective of limiting the $\mathrm{LOH}$ to a minimum, some countries (e.g., Spain) have promoted the creation of short-term units, the purpose of which is to provide quick, coordinated management of patients who have no additional challenges other than decompensation of a chronic condition, such as AHF [6,7].

Nonetheless, while it has been proposed that shortening LOH in AHF is the best way to mitigate expenditures and reduce post-discharge adverse outcome risk [8], it is also feasible that it may worsen shortterm outcomes. Certainly, residual congestion or unsolved residual organ damage is more likely to be present at hospital discharge in patients with a very short period of in-hospital supervised management and treatment. In addition, while well-defined discharge planning and structured outpatient follow-up improve AHF patient outcomes [9], very short hospitalisations could interfere with the complete implementation of such measures. To date, the impact of $\mathrm{LOH}$ on postdischarge outcomes has been poorly explored in the real world scenario. Although randomised clinical trials are the gold standard to unequivocally demonstrate the benefit of new treatment or disease approaches, inpatient hospital registries remain the primary source of real-world data as they include unselected patients representing the full spectrum of HF [10]. Our purpose was to explore the relationship between the LOH and post-discharge outcomes in a large registry of consecutive patients admitted to hospital for AHF. Our hypothesis is that a short duration of hospitalisation does not negatively impact outcomes in AHF. An exploratory stratified analysis by the main hospitalisation departments of AHF patients was also performed.

\section{Methods}

\subsection{Setting}

The LOHRCA (Length Of Hospitalisation and its Relationship with outComes in Acute heart failure) study was an exploratory, secondary analysis within the EAHFE (Epidemiology of Acute Heart Failure in Emergency departments) Registry. This registry was initiated in 2007 and every 2-3 years it carries out a 1-2-month recruitment period of all consecutive patients diagnosed with AHF in Spanish EDs participating in the project. To date, 5 recruitment phases (in 2007, 2009, 2011, 2014, and 2016) have been performed with the participation of 41 EDs from community and university hospitals across Spain (representing about $13 \%$ of the hospitals belonging to the Spanish public healthcare system), enrolling a total of 13,791 AHF patients. The LOHRCA study used the 12,843 patients recruited in phases 2 to 5 since data on $\mathrm{LOH}$ was not recorded in phase 1 . Details of patient inclusion have been reported previously $[11,12]$. Briefly, the principal investigators of each emergency department participating in the EAHFE Registry attend a general meeting held before every recruitment phase in order to homogenize the logistics, protocol definitions, as well as the inclusion and exclusion criteria. All principal investigators are provided with a common dictionary of terms in order to have standard definitions at all centres (available as Supplementary Table 1). The principal investigators then explain protocol instructions to the emergency physicians of their respective centres during a weekly ED meeting preceding patient recruitment. During the recruitment time frame, patient enrolment is done by any attending emergency physician in the participating EDs. These physicians are responsible for the detection of potential cases of patients with AHF. All suspected cases are confirmed by the principal investigator of each centre to ensure the patients meet the diagnostic criteria of AHF based on the Framingham clinical criteria
[13]. If possible, the diagnosis is confirmed by measurement of plasma natriuretic peptide and/or echocardiography during ED or hospital stay, following the current recommendations of the ESC guidelines [14], and this is done in about $92 \%$ of cases. The principal investigator of each centre is responsible for the final diagnostic adjudication of the cases. The only exclusion criterion of the EAHFE Registry is a concurrent primary diagnosis of ST-elevation myocardial infarction (STEMI), which occurs in about 3\% of AHF cases. The EAHFE Registry is only observational, does not include any planned intervention, and the management of patients is entirely based on the attending ED physician decisions.

\subsection{Ethics}

The EAHFE Registry protocol was approved by a central Ethics Committee at the Hospital Universitario Central de Asturias (Oviedo, Spain) with the reference numbers $49 / 2010,69 / 2011,166 / 13$, and $160 / 15$. Due to the non-interventional design of the registry, Spanish legislation allows central Ethical Committee approval, accompanied by notification to the local Ethical Committees. All participating patients gave informed consent to be included in the registry and to be contacted for follow-up. The LOHRCA study was carried out in strict compliance with the Declaration of Helsinki principles.

\subsection{Design and variables recorded}

All patients hospitalised after an ED diagnosis of AHF and discharged alive, in whom data regarding the $\mathrm{LOH}$ and mortality were available, were eligible for this study. The LOHRCA study was designed to analyse outcomes in $4 \mathrm{LOH}$ subgroups. Groups were defined from a previous analysis of outcome prevalence versus time (Fig. 1), and consisted of $\mathrm{LOH} \leq 5,6$ to 10,11 to 15 , and $>15$ days. The $\mathrm{LOH}$ was defined as the calendar day that patients presented to the ED until the calendar day that they were discharged from the hospital.

In addition to the $\mathrm{LOH}$ (classificatory variable), another 22 independent variables regarding demographic data (2 variables), comorbidities (12 variables), baseline status (3 variables) and chronic treatments for $\mathrm{HF}$ ( 5 variables) were recorded to delineate the chronic underlying risk profiles that could potentially impact on the primary endpoints. With respect to the severity of the AHF episode itself, we estimated the risk of each patient using the previously developed

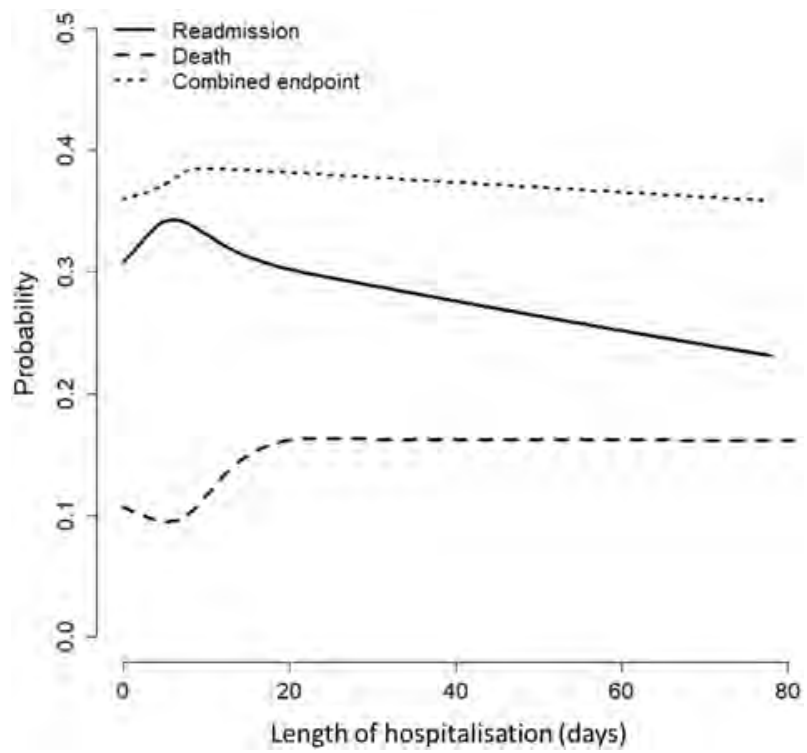

Fig. 1. Probability of adverse outcomes plotted against day by day of length of hospitalisation. 


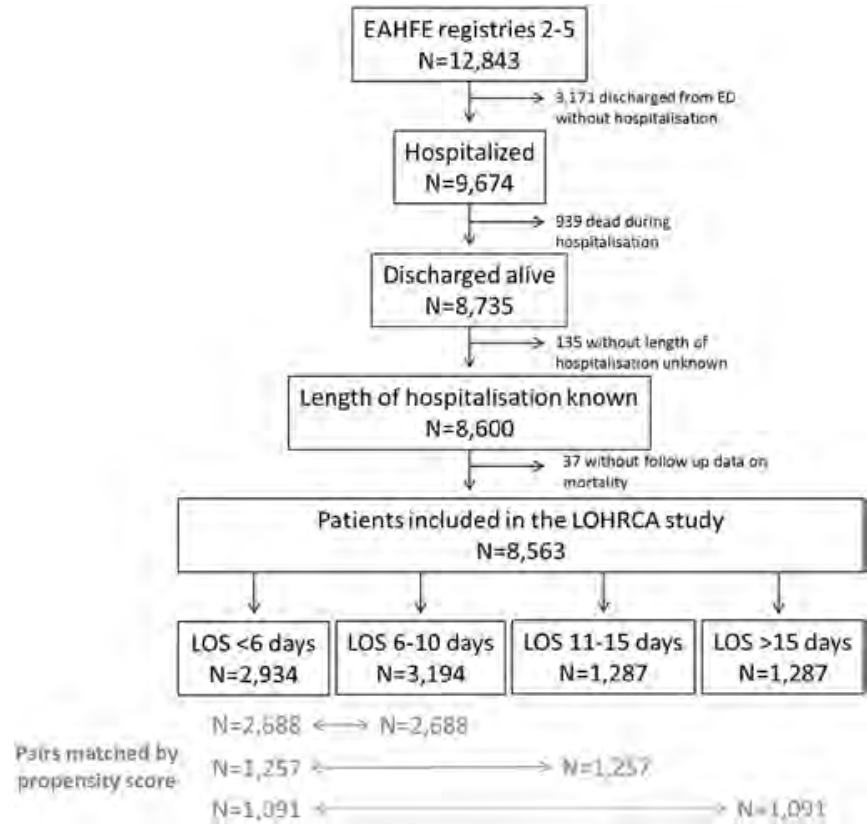

Fig. 2. Flow chart for patient inclusion.

LOS: length of stay.
MEESSI score ${ }^{11}$ and EFFECT score [15], which assess the 30-day risk of death in ED AHF and in hospitalised AHF patients, respectively. For both, the higher the score, the higher the risk. The initial department to which the patient was transferred after ED management was considered responsible for hospitalisation because, although the internal transfer rate between different departments is $<10 \%$ in Spanish hospitals, we did not record further departments to which a patient was moved when the initial department was not the same as the final department from which the patient was discharged home.

\subsection{Outcomes}

We recorded three main post-discharge outcomes, defined as starting at the time of discharge from hospitalisation, and included 90day all-cause death, 90-day readmission due to AHF, and the combined endpoint. The 90-day period was selected because it has been proposed as the vulnerable post-discharge period for patients with AHF [16]. Follow-up was performed by telephone contact and consultation of medical records.

\subsection{Statistical analysis}

Continuous variables are expressed as mean and standard deviation (SD) or median and interquartile range (IQR) if not normally distributed, and discrete variables as absolute values and percentages. Comparison among groups was carried out using one-way ANOVA for continuous variables and the chi square test for discrete variables. Outcomes among the groups of $\mathrm{LOH}$ were compared by means of Cox

Table 1

Overall patient characteristics for the whole series and comparison among the four groups determined by the length of hospitalisation.

\begin{tabular}{|c|c|c|c|c|c|c|c|}
\hline & $\begin{array}{l}\text { Total } \\
N=8563 \\
\mathrm{n}(\%)\end{array}$ & $\begin{array}{l}\text { Missing values } \\
\text { n (\%) }\end{array}$ & $\begin{array}{l}<6 \text { days } \\
N=2934 \\
\mathrm{n}(\%)\end{array}$ & $\begin{array}{l}6-10 \text { days } \\
N=3184 \\
\mathrm{n}(\%)\end{array}$ & $\begin{array}{l}11-15 \text { days } \\
N=1287 \\
\text { n (\%) }\end{array}$ & $\begin{array}{l}>15 \text { days } \\
N=1158 \\
\mathrm{n}(\%)\end{array}$ & $\mathrm{p}$ value \\
\hline Age (years) (mean (SD)) & $80.2(10.2)$ & $10(0.1)$ & $80.9(10)$ & $80.2(10.2)$ & $80.1(10.2)$ & $78.7(10.5)$ & $<0.001$ \\
\hline Female & $4742(55.5)$ & $24(0.3)$ & $1664(56.9)$ & $1786(56.3)$ & $708(55.1)$ & $584(50.6)$ & 0.006 \\
\hline \multicolumn{8}{|l|}{ Comorbidities } \\
\hline Hypertension & $7215(84.4)$ & $16(0.2)$ & $2503(85.5)$ & $2684(84.4)$ & 1079 (83.9) & $949(82.2)$ & 0.146 \\
\hline Heart valve disease & $2282(26.7)$ & $17(0.2)$ & $789(26.9)$ & $819(25.8)$ & $347(27)$ & $327(28.3)$ & 0.746 \\
\hline Atrial fibrillation & 4235 (49.6) & $17(0.2)$ & $1544(52.8)$ & $1546(48.6)$ & $604(47)$ & $541(46.9)$ & $<0.001$ \\
\hline Chronic kidney failure (creatinine $>2 \mathrm{mg} / \mathrm{mL}$ ) & $2298(26.9)$ & $16(0.2)$ & $719(24.6)$ & $863(27.1)$ & $382(29.7)$ & $334(28.9)$ & 0.002 \\
\hline Cerebrovascular disease & 1155 (13.5) & $18(0.2)$ & $413(14.1)$ & $384(12.1)$ & $175(13.6)$ & $183(15.9)$ & 0.016 \\
\hline Peripheral artery disease & $839(9.8)$ & $19(0.2)$ & $281(9.6)$ & $296(9.3)$ & $136(10.6)$ & $126(10.9)$ & 0.648 \\
\hline Chronic obstructive pulmonary disease & $2105(24.6)$ & $23(0.3)$ & $681(23.3)$ & $786(24.7)$ & $336(26.1)$ & $302(26.2)$ & 0.228 \\
\hline Dementia & 993 (13) & $938(11)$ & $324(12.3)$ & $389(13.7)$ & $161(13.9)$ & $119(11.9)$ & 0.488 \\
\hline NYHA class III-IV & $2029(25.1)$ & $478(5.6)$ & $622(22.3)$ & $747(24.8)$ & $330(27.5)$ & $330(30.5)$ & $<0.001$ \\
\hline Left ventricular ejection fraction (\%) (mean (SD)) & $50.98(15.16)$ & $3877(45.3)$ & $51.11(15.12)$ & $51.27(14.96)$ & $50.97(14.96)$ & $49.93(15.92)$ & 0.278 \\
\hline \multicolumn{8}{|l|}{ Chronic treatments at home } \\
\hline Diuretics (any) & $6363(76)$ & $194(2.3)$ & 2184 (75.7) & $2354(75.8)$ & $951(75.7)$ & $874(77.8)$ & 1.018 \\
\hline Renin-angiotensin system inhibitors & $4792(57.3)$ & $195(2.3)$ & $1695(58.7)$ & $1807(58.2)$ & $695(55.3)$ & $595(53)$ & 0.006 \\
\hline Beta-blockers & $3416(40.8)$ & $196(2.3)$ & $1276(44.2)$ & $1188(38.3)$ & $506(40.3)$ & $446(39.7)$ & $<0.001$ \\
\hline Mineralocorticoid-receptor antagonists & $1428(17.1)$ & $193(2.3)$ & $480(16.6)$ & $511(16.5)$ & $209(16.6)$ & $228(20.3)$ & 0.046 \\
\hline Digoxin & 1295 (15.5) & $203(2.4)$ & $460(16)$ & $487(15.7)$ & $177(14.1)$ & $171(15.2)$ & 0.928 \\
\hline \multicolumn{8}{|l|}{ Severity of current heart failure decompensation } \\
\hline MEESSI score (mean (SD)) & $-2.69(1.13)$ & 3526 (41.2) & $-2.83(1.09)$ & $-2.66(1.14)$ & $-2.58(1.12)$ & $-2.52(1.16)$ & $<0.001$ \\
\hline EFFECT score (mean (SD)) & $115.7(25.1)$ & 3865 (45.1) & $113.7(24.6)$ & $116.6(25.2)$ & $117.1(25.9)$ & $117.6(24.8)$ & $<0.001$ \\
\hline
\end{tabular}

MEESSI score estimates the 30-day mortality risk and includes 13 parameters: age, Barthel index, NYHA class, decompensation associated with acute coronary syndrome, low output signs and symptoms, systolic blood pressure, respiratory rate, oxygen saturation, potassium, NT-proBNP, troponin, creatinine, and left ventricular hypertrophy in ECG. The higher the score, the higher the risk.

EFFECT score estimates the 30-day mortality risk and includes 10 parameters: age, cerebrovascular disease, dementia, chronic obstructive pulmonary disease, hepatic cirrhosis, cancer, respiratory rate, systolic blood pressure, urea nitrogen and sodium. The higher the score, the higher the risk. 

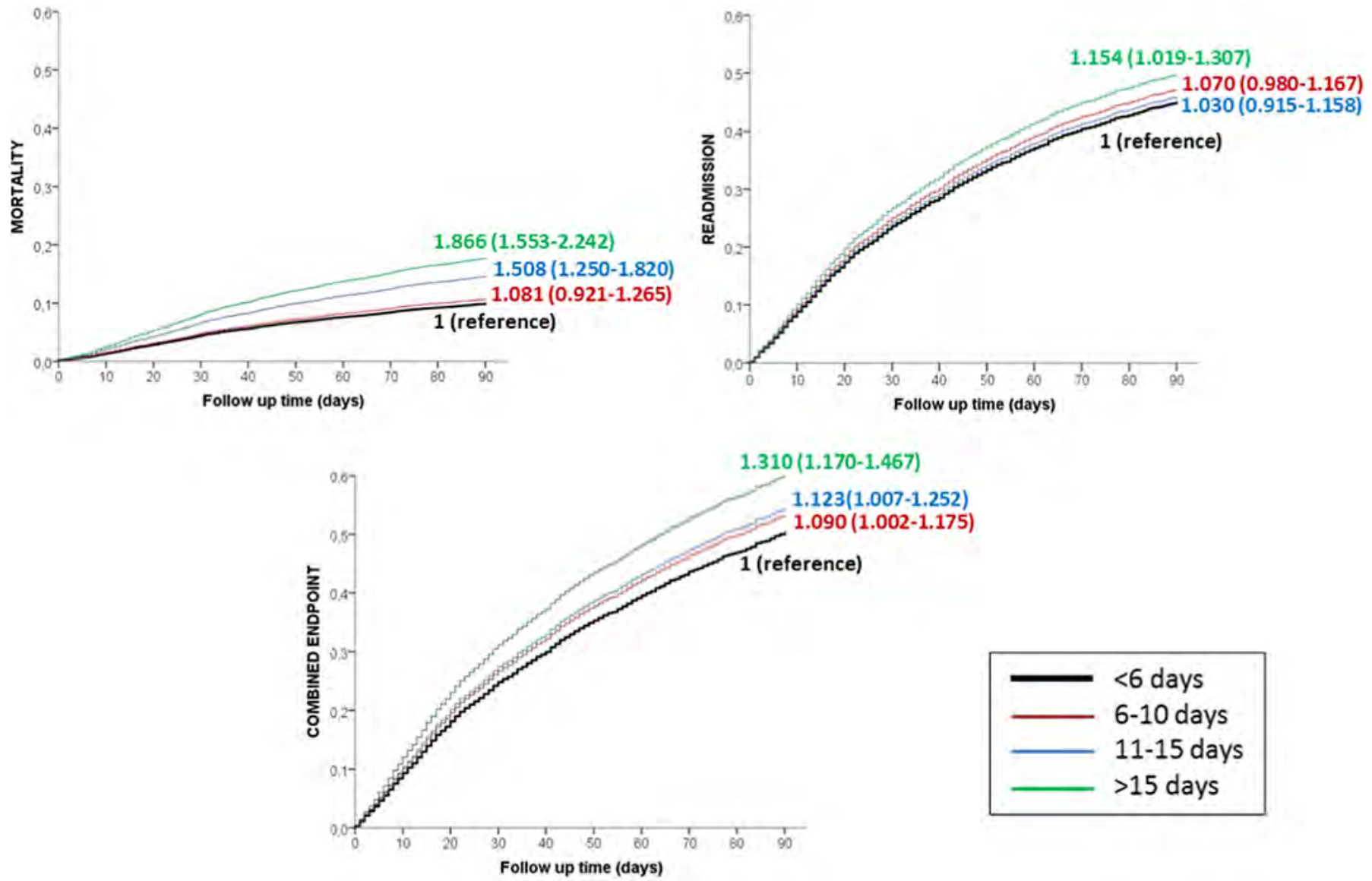

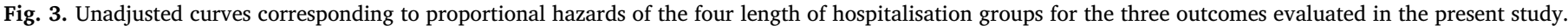

regression analysis and expressed as hazard ratios (HRs) with 95\% confidence intervals (95\% CI) using the shortest LOH stay group ( $<6$ days) as the reference standard. Curves depicting unadjusted proportional hazards were made. Hazard ratios were adjusted for all independent variables of chronic status with a $p<0.10$ in the univariate analysis, and by decompensation severity determined by the MEESSI and EFFECT scores. Additional models of adjustment were created by a combination of the above. Missing values were replaced using the multiple imputation technique, generating 5 datasets with no missing values for the variables included in the adjustment. As sensitivity analysis, hospitalisations $\leq 10$ days were analysed in 1-day periods, with LOH of 0-3 days as the reference standard, in order to detect risks in groups in the shortest $\mathrm{LOH}$. We also planned a stratified analysis of the three outcomes for the four main admission wards in patients hospitalised due to AHF: cardiology, internal medicine, geriatrics and short-stay unit. Statistical significance was accepted if the $95 \%$ confidence interval (CI) of the excluded the value 1 , or the $p$ value was $<0.05$. Since this was an exploratory study, a pre-hoc sample size calculation was not made.

\section{Results}

Of the 12,843 patients included in the EAHFE 2 to 5 registries, 9674 were hospitalised and 8563 were discharged alive and had enough data available to be included in the LOHRCA study (Fig. 2). Overall, the mean age was 80 (SD 10) years, and $55.5 \%$ were women. Comorbidities were common, with the most frequent being hypertension $(84.4 \%)$, atrial fibrillation (49.6\%) and diabetes mellitus (42.9\%) (Table 1). With respect to baseline status, the mean Barthel index was 79 (SD 25), left ventricular ejection fraction $51 \%$ (SD 15 ), and $25.1 \%$ were NYHA class III or IV. A prior episode of AHF was recorded in $60.5 \%$ of patients, and
$57.3 \%$ and $40.8 \%$ were receiving chronic treatment with renin-angiotensin system inhibitors and beta-blockers, respectively. Table 1 shows the remaining data regarding baseline and chronic status. With regard to severity of decompensation, the MEESSI and EFFECT scores were -2.69 (SD 1.13), and 116 (SD 25), respectively (Supplementary Fig. 1).

The median LOH was 7 days (IQR 4-11). The LOH was $<6$ days in 2934 patients (34.3\%), 6-10 in 3184 (37.2\%), 11-15 in 1287 (15.0\%), and $>15$ in 1158 (13.5\%). These groups were different in 10 out of 22 chronic or baseline status variables (Table 1). They also differed in the MEESSI and the EFFECT scores, and the higher the severity of the acute episode (assessed by either score), the longer the LOH (Table 1).

During the 90-day post-discharge period, 975 (11.4\%) patients died, $2760(32.2 \%)$ were readmitted, and $3202(37.4 \%)$ achieved the combined endpoint (Fig. 3). With respect to patients with a LOH of $<6$ days, unadjusted HRs for mortality showed statistically significant increases of $50.8 \%$ and $86.6 \%$ if hospitalised $11-15$ days and $>15$ days, respectively. Unadjusted HRs for 90 -day readmission showed a statistically significant increase of $15.4 \%$ for patients with $\mathrm{LOH}>15$ days, and the 90-day combined endpoint showed statistically significant increases of $9.0 \%, 12.3 \%$ and $31.0 \%$ for cohorts with LOH of $6-10$, 11-15, and > 15 days, respectively (Fig. 3 and Table 2). The models with progressive adjustment showed similar results for 90-day mortality, and statistically significant increases were maintained with the complete adjustment (model 6) for mortality in patients with $\mathrm{LOH}$ $11-15$ days (36.5\% increase vs. $\mathrm{LOH}<6$ days; $95 \%$ CI $13.0 \%$ to $64.9 \%$ ) and $>15$ days $(72.0 \%$ increase vs. LOH $<6$ days, $95 \%$ CI $42.5 \%$ to $107.5 \%$ ). On the other hand, LOH had a neutral effect on 90-day readmission after complete adjustment (model 6), while patients with $\mathrm{LOH}>15$ days had significantly higher rates of the combined endpoint ( $22 \%$ increase vs. $\mathrm{LOH}<6$ days, $95 \%$ CI $9 \%$ to $37 \%$ ) (Table 2 ). The 
Table 2

Unadjusted and adjusted hazard ratios (HR) of adverse outcomes per length of hospitalisation group.

\begin{tabular}{|c|c|c|c|c|}
\hline & $<6$ days & $6-10$ days & 11-15 days & $>15$ days \\
\hline \multicolumn{5}{|l|}{ 90-day all-cause mortality } \\
\hline Unadjusted HR & 1 (Reference) & $1.081(0.921-1.265)$ [0.339] & $1.508(1.250-1.820)[<0.001]$ & $1.866(1.553-2.242)[<0.001]$ \\
\hline Adjusted HR (model 1) & 1 (Reference) & $1.064(0.906-1.249)[0.447]$ & $1.441[1.193-1.740)[<0.001]$ & $1.850(1.536-2.227)[<0.001]$ \\
\hline Adjusted HR (model 2) & 1 (Reference) & $0.996(0.847-1.171)[0.958]$ & $1.351(1.118-1.631)[0.002]$ & $1.651(1.371-1.989)[<0.001]$ \\
\hline Adjusted HR (model 3) & 1 (Reference) & $1.049(0.893-1.232)[0.562]$ & $1.455(1.206-1.756)[<0.001]$ & $1.847(1.537-2.219)[<0.001]$ \\
\hline Adjusted HR (model 4) & 1 (Reference) & $0.986(0.839-1.158)[0.862]$ & $1.325(1.097-1.599)[0.003]$ & $1.600(1.329-1.928)[<0.001]$ \\
\hline Adjusted HR (model 5) & 1 (Reference) & $1.040(0.885-1.222)[0.635]$ & $1.407(1.164-1.699)[<0.001]$ & $1.797(1.490-2.167)[<0.001]$ \\
\hline Adjusted HR (model 6) & 1 (Reference) & $1.009(0.859-1.186)[0.911]$ & $1.365(1.130-1.649)[0.001]$ & $1.720(1.426-2.075)[<0.001]$ \\
\hline Adjusted HR (by propensity score matching) & 1 (Reference) & $\begin{array}{l}0.985(0.829-1.170) \\
{[0.860]}\end{array}$ & $\begin{array}{l}1.480(1.174-1.864) \\
{[<0.001]}\end{array}$ & $\begin{array}{l}1.830(1.441-2.324) \\
{[<0.001]}\end{array}$ \\
\hline \multicolumn{5}{|l|}{ 90-day readmission due to $\mathrm{AHF}$} \\
\hline Unadjusted HR & 1 (Reference) & $1.070(0.980-1.167)[0.131]$ & $1.030(0.915-1.158)[0.628]$ & $1.154(1.019-1.307)[0.024]$ \\
\hline Adjusted HR (model 1) & 1 (Reference) & $1.057(0.968-1.154)[0.213]$ & $1.001(0.889-1.126)[0.992]$ & $1.103(0.973-1.250)[0.127]$ \\
\hline Adjusted HR (model 2) & 1 (Reference) & $1.052(0.964-1.148)[0.256]$ & $1.005(0.893-1.130)[0.939]$ & $1.121(0.990-1.270)[0.073]$ \\
\hline Adjusted HR (model 3) & 1 (Reference) & $1.063(0.974-1.160)[0.173]$ & $1.024(0.910-1.152)[0.696]$ & $1.148(1.014-1.300)[0.030]$ \\
\hline Adjusted HR (model 4) & 1 (Reference) & $1.052(0.964-1.149)[0.256]$ & $0.993(0.883-1.118)[0.911]$ & $1.091(0.962-1.237)[0.175]$ \\
\hline Adjusted HR (model 5) & 1 (Reference) & $1.050(0.962-1.147)[0.276]$ & $0.993(0.889-1.126)[0.997]$ & $1.103(0.974-1.251)[0.123]$ \\
\hline Adjusted HR (model 6) & 1 (Reference) & $1.046(0.958-1.142)[0.316]$ & $0.987(0.877-1.111)[0.830]$ & $1.083(0.955-1.228)[0.215]$ \\
\hline Adjusted HR (by propensity score matching) & 1 (Reference) & $\begin{array}{l}1.019(0.928-1.119) \\
{[0.690]}\end{array}$ & $\begin{array}{l}0.982(0.856-1.128 \\
{[0.799]}\end{array}$ & $\begin{array}{l}1.026(0.883-1.192) \\
{[0.883-1.192]}\end{array}$ \\
\hline \multicolumn{5}{|l|}{ 90-day combined endpoint } \\
\hline Unadjusted HR & 1 (Reference) & $1.090(1.002-1.175)[0.044]$ & $1.123(1007-1.252)[0.038]$ & $1.310(1.170-1.467)[<0.001]$ \\
\hline Adjusted HR (model 1) & 1 (Reference) & $1.075(0.988-1.169)[0.092]$ & $1.087(0.974-1.213)[0.136]$ & $1.248(1.113-1.400)[<0.001]$ \\
\hline Adjusted HR (model 2) & 1 (Reference) & $1.064(0.978-1.156)[0.148]$ & $1.084(0.972-1.209)[0.149]$ & $1.256(1.120-1.407)[<0.001]$ \\
\hline Adjusted HR (model 3) & 1 (Reference) & $1.080(0.993-1.173)[0.072]$ & $1.115(0.999-1.173)[0.052]$ & $1.301(1.162-1.457)[<0.001]$ \\
\hline Adjusted HR (model 4) & 1 (Reference) & $1.062(0.977-1.155)[0.157]$ & $1.069(0.958-1.193)[0.235]$ & $1.222(1.090-1.369)[0.001]$ \\
\hline Adjusted HR (model 5) & 1 (Reference) & 1.065 (0.979-1.159) [0.141] & $1.077(0.979-1.202)[0.184]$ & $1.232(1.099-1.382)[<0.001]$ \\
\hline Adjusted HR (model 6) & 1 (Reference) & $1.058(0.973-1.151)[0.190]$ & $1.066(0.955-1.190)[0.256]$ & $1.216(1.084-1.364)[0.001]$ \\
\hline Adjusted HR (by propensity score matching) & 1 (Reference) & $\begin{array}{l}1.031(0.943-1.127) \\
{[0.596]}\end{array}$ & $\begin{array}{l}1.066(0.936-1.231) \\
{[0.335]}\end{array}$ & $\begin{array}{l}1.174(1.022-1.347) \\
{[0.023]}\end{array}$ \\
\hline
\end{tabular}

AHF: acute heart failure.

Bold numbers denote comparisons with p values $<0.05$

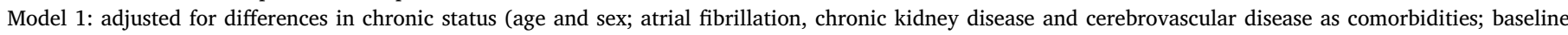
Barthel index and NYHA class; and chronic treatment with renin-angiotensin system inhibitors beta-blockers and mineralcorticosteroid-receptor antagonists).

Model 2: adjusted for the MEESSI score.

Model 3: adjusted for the EFFECT score.

Model 4: adjusted for differences in chronic status and the MEESSI score.

Model 5: adjusted for differences in chronic status and the EFFECT score.

Model 6: adjusted for differences in chronic status, the MEESSI and the EFFECT score.

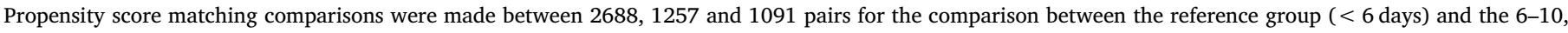
11-15 and > 15 days groups, respectively.

detailed daily analysis of $\mathrm{LOH}$ during the first 10 days showed no differences in adjusted HRs for mortality, although there were increases in the adjusted HR for readmissions and the composite endpoint in patients with a LOH of 8 and 9 days compared with 0-3 days (Fig. 4).

Stratified analysis was performed according to whether patients had initially been admitted to cardiology (1911 patients, 22.3\%), internal medicine $(4716,43.4 \%)$, geriatrics $(620,7.2 \%)$ or a short stay unit $(1408,16.4 \%)$. With few exceptions, similar patterns of HRs were observed in post-discharge outcomes for the four departments (Fig. 5). Increased mortality was observed in patients hospitalised $>15$ days, irrespective of the initial admission department, with increments ranging from $66 \%$ (internal medicine) to $216 \%$ (geriatrics). Conversely, there was no increased readmission risk, and only a significant increment in risk of combined endpoint was observed in patients initially hospitalised in cardiology or short-stay units for $>15$ days $(29 \%$ and $98 \%$, respectively).

\section{Discussion}

The results of the LOHRCA study were obtained from a consecutive cohort with prospective collection of clinical data of patients hospitalised for AHF in 41 Spanish hospitals and provide three main findings. First, short hospitalisations were not associated with an increased risk of adverse post-discharge outcomes during the subsequent 90 days, while the risk of presenting an adverse event increased in patients hospitalised for $>15$ days. Second, while mortality increased with a longer LOH, readmission did not. And third, the department where the patient had initially been hospitalised did not seem to influence the previous two findings.

Our results suggest that short hospitalisations are a safe and even a recommendable option for patients with AHF, since after adjusting for potential differences in baseline and chronic status as well as for the severity of decompensation, neither mortality nor readmission increased when the LOH was 10 or less days. After this time point, we found that mortality progressively increased with a lengthening in the $\mathrm{LOH}$, with a $73 \%$ increase in patients in whom the LOH surpassed 15 days compared to those not surpassing 5 days. This finding is in line with recent data from a Polish study of 765 patients discharged from 32 cardiology wards. In this study, mortality increased $120 \%$ during an average 414-day follow-up in patients with an index hospitalisation exceeding 21 days compared to patients hospitalised $<7$ days [17]. Similarly, Sud et al. reported a $28 \%$ increase in 30-day all-cause mortality in 58,230 AHF patients admitted to any hospital ward (not only cardiology) in Ontario, Canada for 9 days or more compared with those with a LOH of 5-6 days [18]. Therefore, our data confirm and expand the direct relationship between $\mathrm{LOH}$ and the risk of death reported in such studies. As we prospectively recorded clinical data (in contrast with previous studies that were based on administrative data 

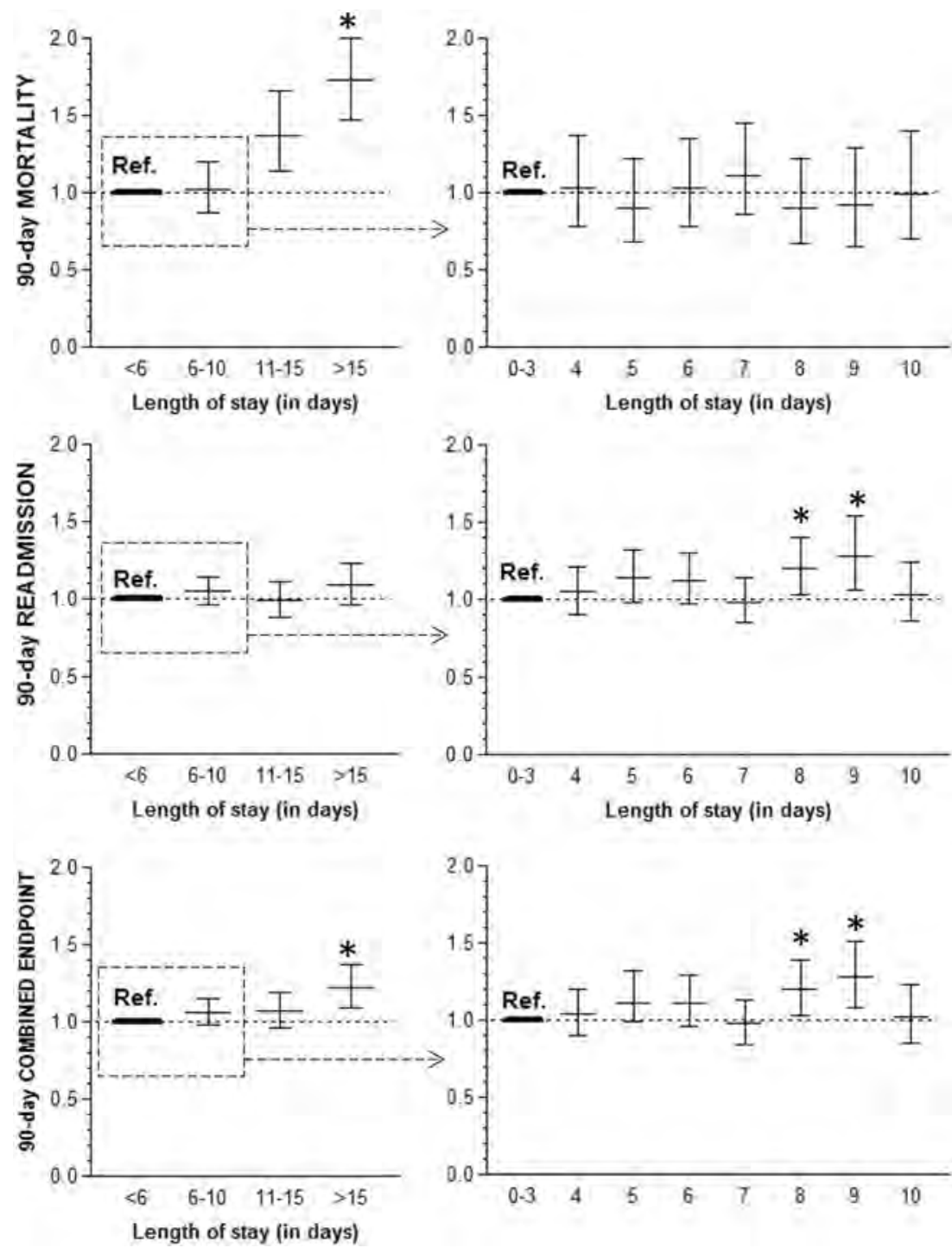

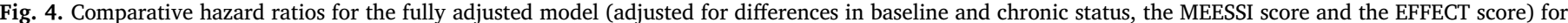

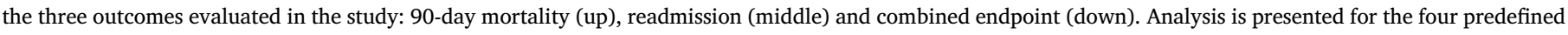
length of hospitalisation groups (left) and detailed day by day for the first 10 days (right).

Asterisks indicate $p<0.05$ respect to reference group (Ref.)

collection), we were able to include the severity of decompensation in the adjustment of our estimations. However, although our results were very consistent in all the adjusted models we developed, an increase in mortality with a lengthening of LOH may just signal a more vulnerable population requiring longer hospitalisation and at higher risk of postdischarge death rather than demonstrating a direct influence of $\mathrm{LOH}$ in the risk of death.

Conversely, we did not detect an increase in 90-day readmission rates related to $\mathrm{LOH}$. This finding is in contrast with previous studies assessing the relationship between $\mathrm{LOH}$ and post-discharge readmission [18-21]. While two American studies have demonstrated that only longer hospitalisations are related to all-cause and HF-related readmissions $[19,20]$, the Canadian Sud et al. study reported the same finding for all-cause readmission but with a U-shape relationship for HF-related readmission, with patients with both the the shortest and longest LOH being at increased risk [18]. By contrast, analysis of the 6827 patients from 27 countries included in the ASCEND-HF trial showed that a longer $\mathrm{LOH}$ was associated with a lower risk in readmission [21]. Therefore, our findings are remarkably different from those obtained in these previous studies, as we failed to detect any relationship between $\mathrm{LOH}$ and the risk of post-discharge readmission.
Hypothetically, the fact that we accounted for the severity of the episode could have contributed to this absence of relationship. Remarkably, only HF-related readmission was taken into account in the LOHRCA study. Nonetheless, from all the information currently available, it seems evident that while the relationship between LOH and post-discharge mortality is clear and direct, the existence and the way of the relationship with post-discharge readmission risk is still unclear and needs further studies.

It is of note that we found a relatively uniform increase in mortality in long hospitalisations across the most frequent departments and specialties involved in in-hospital AHF care. While our results are unique in that this approach to investigate the effect on post-discharge outcomes in individual departments has not previously been performed by other authors, they are contrary to many findings suggesting that the management of AHF by cardiologists may have better outcomes [22-24]. It should be noted that the results of the LOHRCA study cannot be interpreted as a result of differences in the performance of these specialities managing AHF patients during admission, but rather refer to outcomes obtained during the vulnerable phase following patient discharge. As previously commented, one possible explanation is that an increased LOH is just a marker of patients with the highest risk, 


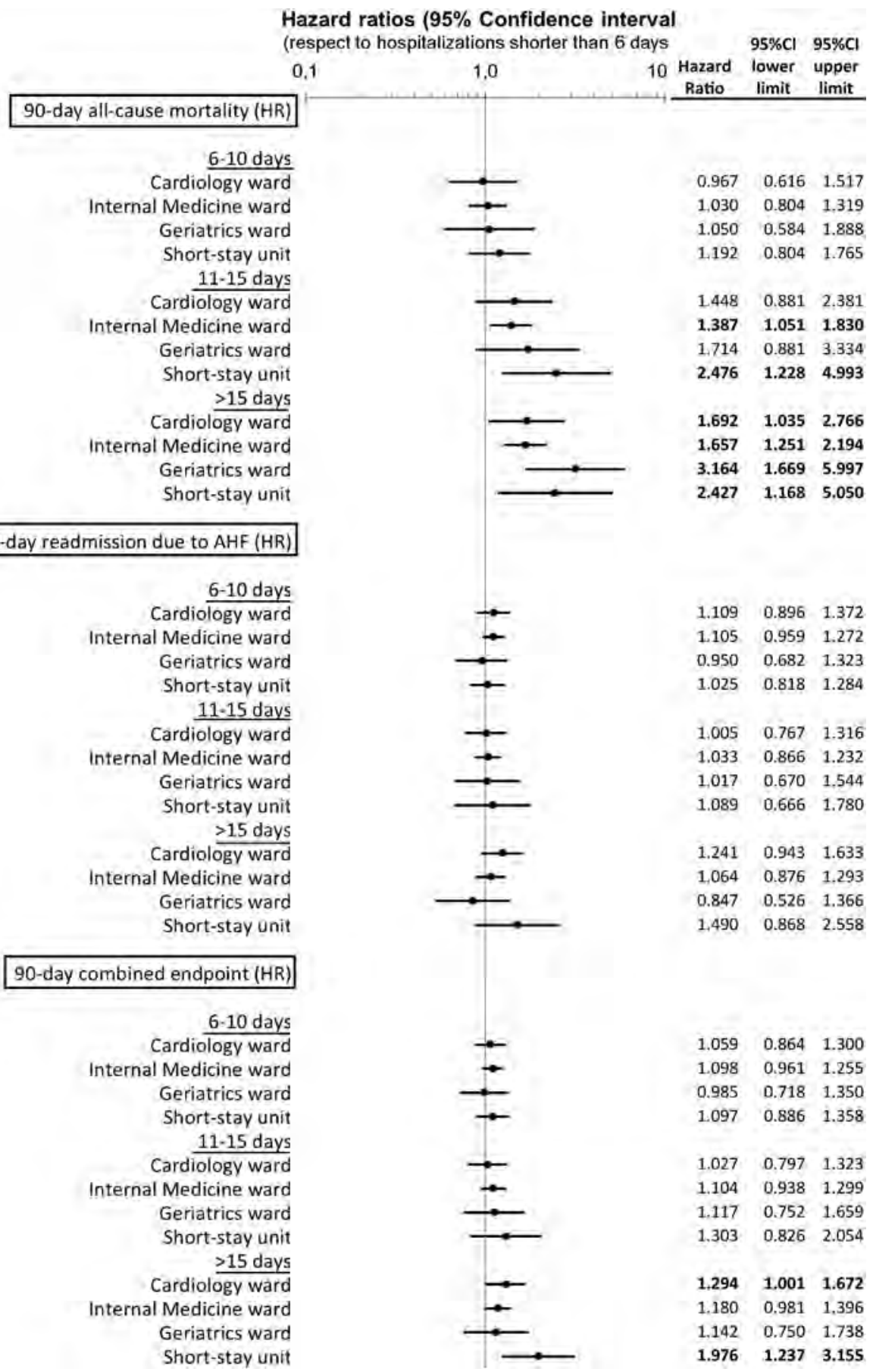

Fig. 5. Stratified analysis of the effect of length of hospitalisation on 90-day outcomes according to the department of hospitalisation (fully adjusted model). Bold numbers in the right columns denote $p$ value $<0.05$.

and does not directly cause the increase in mortality observed. We have tried to limit this possibility by making multiple adjustments, thereby minimizing the potential effect of the different chronic or acute patient profiles, although unknown confounders may persist. It is well known that for patients experiencing an episode of AHF, the average survival is 2 years, and the most vulnerable period is the 3-month window immediately after discharge [16,25]. Reducing persistent subclinical congestion, increasing the use of disease-modifying heart failure therapies, and ensuring optimal transitions of care after hospital discharge have been described as essential steps in improving outcomes for AHF patients [24]. Nonetheless, our findings suggest that increases in $\mathrm{LOH}$ do not achieve greater or better implementation of these key steps.

Again, a similar pattern of readmission was found for the four departments, with no increase of readmission risk associated with a longer LOH. Only the combined endpoint occurred more often in patients initially managed in the cardiology department or in the short-stay units and who had a $\mathrm{LOH}>15$ days. One limitation which might explain this finding is that we do not know how frequent discharge plans were implemented by each department. A recent meta-analysis of 41 randomised trials testing transitional care interventions demonstrated that implementation of transitional plans at AHF patient discharge achieves a significant reduction of $8 \%$ and $29 \%$ in the risk of rehospitalisation and ED visits, respectively [26]. As shown by our results on mortality, it 
is clear that a longer LOH with a greater opportunity for intervention was not successful in changing outcomes. Albeit not statistically significant, our finding of a higher increment of readmission (49\%) in patients hospitalised longer than 15 days and who were initially admitted to short-stay units (on top of the $143 \%$ of increase in mortality) probably contributed to the significant increment (98\%) in the combined endpoint in the same group of patients. Many authors have underlined the importance of candidate selection to define which patients should be admitted to short-stay units, as failure to do this usually leads to prolonged hospitalisations $[7,8,27,28]$.

Our study has some limitations. First, this is a secondary analysis limited to hypothesis generation that requires confirmation in future trials. Second, since there was no sample size calculation due to the exploratory nature of the study, a type-II error cannot be excluded in some of the estimations made, especially in the stratified analysis by departments (due to the small number of events in certain outcomes and/or departments). Third, in this real-life cohort without intervention, attending physicians followed their usual local protocols and did not receive any specific instructions about the precise time for hospital discharge and patient transition. Fourth, the patients were from a single country with a universal public health care system, and since international heterogeneity in organisational and transition processes is high [29], external validation of our results should be carried out in further studies in other countries with different healthcare system models. And fifth, we recorded the department which was responsible for admission once emergency department care was completed, but we did not track further patient transfers from the initial department to others. Therefore, post-discharge outcomes cannot entirely be attributed to the management of the department to which patients were initially admitted. An example of this limitation is the short-stay units where, despite most of the participating hospitals having a LOH limited to $96 \mathrm{~h}$, some patients initially admitted to these units had a $\mathrm{LOH}$ of $>10$ (and even 15) days, probably because they were moved to other departments for reasons we do not know.

Despite these limitations, we can conclude that short hospitalisations in AHF patients are not associated with poorer outcomes, and that for the particular case of all-cause mortality, patients hospitalised longer than 10 days could be at increased risk. No large differences in outcomes were observed among the main departments responsible for the initial hospitalisation.

Supplementary data to this article can be found online at https:// doi.org/10.1016/j.ejim.2019.08.007.

\section{Acknowledgements}

This study was partially supported by competitive grants from the Instituto de Salud Carlos III supported with funds from the Spanish Ministry of Health and FEDER (PI15/01019, PI15/00773, PI18/00393, PI18/00456), Catalonia Government (SGR 2009/1385, 2014/0313, 2017/1424), and Fundació La Marató de TV3 (2015/2510). The ICAResearch Group has received unrestricted funding from Novartis and Orion Pharma. The design of the study, patient inclusion, data analysis, discussion and final conclusions were exclusively carried out by the authors with no participation of the granters.

The authors have nothing to disclose in relationship with this manuscript.

\section{References}

[1] Voigt J, Sasha John M, Taylor A, Krucoff M, Reynolds MR, et al. A reevaluation of the costs of heart failure and its implications for allocationof health resources in the United States. Clin Cardiol 2014;37:312-21.

[2] Mozaffarian D, Benjamin EJ, Go AS, Arnett DK, Blaha MJ, Cushman M, et al. Heart disease and stroke statistics-2016 update: a reportfrom the American Heart Association. Circulation. 2016;133:e38-360.

[3] Shafie AA, Tan YP, Ng CH. Report demonstrating the majority of costs in HF are due to hospitalizations. Heart Fail Rev 2018;23:131-45.

4] Krumholz HM. Post-hospital syndrome: a condition of generalized risk. N Engl J Med 2013;368:100-2.

[5] Cotter G, Davison BA, Milo O, Bourge RC, Cleland JG, Jondeau G, et al. Predictors and associations with outcomes of length of hospital stay in patients with acute heart failure: results from VERITAS. J Card Fail 2016;22:815-22.

[6] Strøm C, Stefansson JS, Fabritius ML, Rasmussen LS, Schmidt TA, Jakobsen JC. Hospitalisation in short-stay units for adults with internal medicine diseases and conditions. Cochrane Database Syst Rev 2018(8):CD012370.

[7] Richard Espiga F, Mòdol Deltell JM, Martín-Sánchez FJ, Fernández Sierra A Fernández Pérez C, Juan Pastor A. Impact of an emergency department short-stay unit on clinical management and quality of hospital care indicators. Emergencias. 2017:29:147-53

[8] Jacob Rodríguez J. Short-stay units: a safe, winning bet for hospitals. Emergencias. 2017;29:145-6.

[9] Van Spall HGC, Rahman T, Mytton O, Ramasundarahettige C, Ibrahim Q, Kabali C, et al. Comparative effectiveness of transitional care services in patients discharged from the hospital with heart failure: a systematic review and network meta-analysis. Eur J Heart Fail 2017;19:1427-43.

[10] Ambrosy AP, Fonarow GC, Butler J, Chioncel O, Greene SJ, Vaduganathan M, et al. The global health and economic burden of hospitalization for heart failure. Lessons learned from hospitalized heart failure registries. JAMA 2014;63:1123-33.

[11] Miró Ò, Rosselló X, Gil V, Martín-Sánchez FJ, Llorens P, Herrero-Puente P, et al. Predicting 30-day mortality for patients with acute heart failure in the emergency department: a cohort study. Ann Intern Med 2017;167:698-705.

[12] Miró O, Llorens P, Escalada X, Herrero P, Jacob J, Gil V, et al. Analysis of the different factors of prehospital care for patients with acute heart failure in Spain. Emergencias 2017;29:223-30.

[13] Ho KKL, Anderson KM, Kannel WB, Grosssman W, Levy D. Survival after the onset of congestive heart failure in Framingham heart study subjects. Circulation 1993;88:107-15.

[14] Ponikowski P, Voors AA, Anker SD, Bueno H, Cleland JG, Coats AJ, et al. 2016 ESC guidelines for the diagnosis and treatment of acute and chronic heart failure: The Task Force for the diagnosis and treatment of acute and chronic heart failure of the European Society of Cardiology (ESC). Developed with the special contribution of the Heart Failure Association (HFA) of the ESC. Eur Heart J 2016;37:2129-200.

[15] Lee DS, Austin PC, Rouleau JL, Liu PP, Naimark D, Tu JV. Predicting mortality among patients hospitalized for heart failure. Derivation and validation of a clinical model. JAMA 2003;290:2581-7.

[16] Greene SJ, Fonarow GC, Vaduganathan M, Khan SS, Butler J, Gheorghiade M. The vulnerable phase after hospitalization for heart failure. Nat Rev Cardiol 2015;12:220-9.

[17] Zaprutko J, Michalak M, Nowicka A, Dankowski R, Drożdż J, Ponikowski P, et al. Hospitalisation length and prognosis in heart failure patients. Kardiol Pol 2017;75:323-31.

[18] Sud M, Yu B, Wijeysundera HC, Austin PC, Ko DT, Braga J, et al. Associations between short or long length of stay and 30-day readmission and mortality in hospitalized patients with heart failure. JACC Heart Fail 2017;5:578-88.

[19] Arora S, Lahewala S, Hassan Virk HU, Setareh-Shenas S, Patel P, Kumar V, et al Etiologies, trends, and predictors of 30-day readmissions in patients with diastolic heart failure. Am J Cardiol 2017;120:616-24.

[20] Mirkin KA, Enomoto LM, Caputo GM, Hollenbeak CS. Risk factors for 30-day readmission in patients with congestive heart failure. Heart Lung 2017;46:357-62.

[21] Eapen ZJ, Reed SD, Li Y, Kociol RD, Armstrong PW, Starling RC, et al. Do countries or hospitals with longer hospital stays for acute heart failure have lower readmission rates?: findings from ASCEND-HF. Circ Heart Fail 2013;6:727-32.

[22] Jong P, Gong Y, Liu PP, et al. Care and outcomes of patients newly hospitalized for heart failure in the community treated by cardiologists compared with other specialists. Circulation 2003;108:184-91.

[23] Boom NK, Lee DS, Tu JV. Comparison of processes of care and clinical outcomes for patients newly hospitalized for heart failure attended by different physician specialists. Am Heart J 2012;163:252-9.

[24] Uthamalingam S, Kandala J, Selvaraj V, et al. Outcomes of patients with acute decompensated heart failure managed by cardiologists versusnoncardiologists. Am J Cardiol 2015;115:466-71.

[25] Arrigo M, Nijst P, Rudiger A. Optimising heart failure therapies in the acute setting. Card Fail Rev 2018;4:38-42.

[26] Vedel I, Khanassov V. Transitional care for patients with congestive heart failure: a systematic review and meta-analysis. Ann Fam Med 2015;13:562-71.

[27] Martín-Sánchez FJ, Perdigones J, Ferré Losa C, Llopis F, Navarro Bustos C, Borraz Ordas C, et al. 180-day risk of mortality in older patients admitted to short-stay units: the 6-Month Short-Stay Unit (6M UCE) Score. Emergencias 2018;30:315-20.

[28] Miró Ò, Carbajosa V, Peacock WF, Llorens P, Herrero P, Jacob J, et al. The effect of a short-stay unit on hospital admission and length of stay in acute heart failure: REDUCE-AHF study. Eur J Intern Med 2017;40:30-6.

[29] Bhatt AB, Cheeran DD, Shemisa K, Roy L, Manz BN, Vigen R, et al. Physician-specific practice patterns about discharge readiness and heart failure utilization outcomes. Circ Cardiovasc Qual Outcomes 2018;11:e004365. 